\title{
Anticytokine therapies in systemic lupus erythematosus
}

\author{
Antonio La Cava \\ Division of Rheumatology, Department of Medicine, University of California Los Angeles, 1000 \\ Veteran Avenue 32-59, Los Angeles, CA 90095-1670, USA Tel.: +1 3102674975 Fax: +1 310206 \\ 8606 alacava@mednet.ucla.edu
}

\section{Abstract}

The dysfunctional immune response that characterizes systemic lupus erythematosus (SLE) associates with an unbalanced production of soluble mediators that are crucial in promoting and sustaining chronic inflammation. The successful use of biologics in several autoimmune diseases has led to studies in SLE aimed at contrasting the proinflammatory responses that contribute to tissue and organ damage in the disease. Several approaches have been developed and tested as potential therapeutic agents in SLE in preclinical studies and in clinical trials. This article provides an overview on antibody-based approaches in SLE that, although preliminary, have the potential to expand the current therapeutic possibilities in the disease.

\section{Keywords}

anticytokine therapy; clinical trial; cytokine; immunotherapy; systemic lupus erythematosus

Systemic lupus erythematosus (SLE) is an autoimmune disease that affects multiple tissues and systems and is characterized by significant interindividual variability in clinical manifestations and organ involvement. Despite new and improved therapeutic options having positively impacted the prognosis of SLE, some SLE patients experience an aggressive disease course and/or unresponsiveness to therapy. Moreover, the risk of fatal outcomes and the damaging side effects of immunosuppressive therapies in SLE (increased risk of infection, infertility and liver toxicity, among others) call for an improvement in the current therapeutic management of SLE.

From a pathogenesis standpoint, unbalanced immune homeostasis and aberrant autoreactivity in SLE associate with inflammatory cells and the production of autoantibodies that play key roles in the development of tissue damage. Since cytokines promote and/or sustain the proinflammatory environment, anticytokine therapies have come under scrutiny as new modalities to dampen or reduce the deleterious inflammatory responses associated with hyperactivity of immune cells and autoantibody production. The envisioned benefits could significantly affect patients that cannot tolerate or are unresponsive to conventional therapies. They could also prove beneficial in reducing dosages of immunosuppressive drugs (and thus side effects) and improving clinical control (e.g., reduce risk of flare-ups) in patients that respond to therapy.

\section{(C) 2010 Future Medicine Ltd}

Financial \& competing interests disclosure: Antonio La Cava is supported by grants from the NIH (NIH AR53239) and the Southern California Chapter of the Arthritis Foundation. The author has no other relevant affiliations or financial involvement with any organization or entity with a financial interest in or financial conflict with the subject matter or materials discussed in the manuscript apart from those disclosed.

No writing assistance was utilized in the production of this manuscript. 


\section{Antibody-based therapies in systemic lupus erythematosus}

Monoclonal antibodies (mAbs) and fusion (or chimeric) proteins that target proinflammatory cytokines have been used in the clinic for several rheumatic diseases, often with great success (a classical example is the use of TNF inhibitors in rheumatoid arthritis [RA]). The advantage in using $\mathrm{mAbs}$ is that they target a single molecule or its receptor(s) with great specificity and can be produced in large amounts by hybridomas. The mAbs that have been used in the clinic include murine, chimeric, humanized and fully human antibodies. In particular, chimerization consists of the replacement of the mouse constant domains with their human counterparts, and humanization is achieved by transplanting the complementary determining regions of murine antibodies (the parts that interact with the antigen) into a fully human antibody framework. While reducing immunogenicity, this procedure still leads to mAbs with murine components against which the host immune system can mount an immune response, leading to a reduced therapeutic efficacy over time. The order indicated above (murine, chimeric, humanized and fully human antibodies) somehow reflects a chronological approach in the development of these molecules as therapeutics, which have progressively become less antigenic/immunogenic (owing to reduced murine components), with resulting increased efficacy, prolonged half-life and availability for continuous use in patients.

This article focuses on anticytokine mAbs used as new therapeutic approaches in SLE. Other approaches (e.g., immune cell-based intervention and costimulatory blockade and inhibition of complement factors) have been reviewed elsewhere [1].

\section{Cytokines as therapeutic targets in systemic lupus erythematosus}

Inflammatory responses in SLE can be favored and/or sustained by the availability of cytokines that are overexpressed systemically and/or in local tissues. Proinflammatory cytokines such as TNF- $\alpha$, IL-1, $-6,-12,-15,-18$ and IFN- $\alpha$ and $-\gamma$ are upregulated in SLE and play important roles in the inflammatory processes that leads to tissue and organ damage. Thus, many of these cytokines have been considered potential targets for the reduction of chronic inflammation in SLE. Blockade of these cytokines has been studied in preclinical models, with the acknowledged caveat that murine lupus models and human SLE may not fully share patho genetic mechanisms. For some cytokines - which are reviewed below - specific biologics have been developed and tested in clinical trials.

\section{- TNF- $\alpha$}

The role of TNF- $\alpha$ in SLE is controversial. TNF- $\alpha$ promotes apoptosis and significantly affects the activity of B cells, T cells and dendritic cells (DCs). In different strains of lupus mice, the expression of TNF- $\alpha$ is often variable, and beneficial effects on the disease can be observed either after administration of TNF or upon TNF blockade [2-4]. In kidney inflammation, the renal expression of TNF is usually increased [5]. In lupus mice, skin disease may be TNF dependent, and anti-TNF treatment can deteriorate nephritis. In humans, some studies have found relatively low concentrations of serum TNF- $\alpha$, while other studies have found elevated amounts or no significant differences between SLE patients and healthy controls. Similarly, high TNF- $\alpha$ has been described in both active and inactive SLE [6-8]. Furthermore, TNF- $\alpha$ levels might correlate with clinical disease because they are increased in lupus nephritis in relation to the activity of renal disease [9].

Infliximab \& etanercept-The TNF blockers that have been successful in the management of RA, Crohn's disease and psoriasis are known to induce autoantibodies and lupus-like syndromes. Thus, their use in SLE is controversial [10-12]. Although with the cessation of the administration of TNF inhibitors, the lupus-like symptoms and most auto-antibodies disappear 
(they are IgM and possibly are not pathogenic), it has been reported that a few RA patients who use TNF-blockers can develop nephritis [13,14].

In SLE, the use of anti-TNF antibodies has been associated with amelioration of poly-arthritis, cutaneous manifestations, disease activity, proteinuria and nephritis, but also severe infusion reaction $[15,16]$. An open-label study of infliximab in a small number of SLE patients with arthritis and/or lupus nephritis that were refractory to standard therapy has shown clinical improvement and an increased risk of infection [17]. However, it appears that anti-TNF treatment is not promising in SLE, after the termination of studies on TNF blockade in a Phase II/III multicenter trial where infliximab was combined with azathioprine in lupus membranous nephritis, and also in a randomized, double-blind, multicenter Phase II study that evaluated safety and tolerability of etanercept in patients with active lupus nephritis.

\section{- Interferons}

Both type I (IFN- $\alpha$ ) and type II (IFN- $\gamma$ ) interferons have been implicated in the pathogenesis of SLE, with IFN- $\alpha$ being a key player in inflammation and immune hyperactivity in the disease owing to its ability to directly affect $\mathrm{T}$ cells and $\mathrm{B}$ cells and induce the activation of peripheral DCs.

IFN- $\boldsymbol{\alpha}$-DNA-containing immune complexes in lupus serum stimulate plasmacytoid DCs to produce IFN- $\alpha[18,19]$. IFN- $\alpha$ levels often correlate with anti-dsDNA antibody production, complement activation and IL-10 production [20]. This cytokine promotes activation, differentiation, survival and antibody production in B cells. In SLE, patients can have increased levels of IFN- $\alpha$, which in turn promotes the expression of interferon-regulated inflammatory genes in the peripheral blood mononuclear cells of the SLE patients (a characteristic often referred to as the 'interferon signature').

Sifalimumab-This human antibody that blocks multiple IFN- $\alpha$ subtypes is currently being tested in Phase Ib and IIa clinical trials, to evaluate safety and tolerability of multiple intravenous and subcutaneous doses in SLE.

Rontalizumab-This humanized mAb against IFN- $\alpha$ (rhuMAb IFN- $\alpha$ ) is in a Phase II, randomized, double-blind, placebo-controlled trial that evaluates the efficacy and safety in patients with moderately to severely active SLE.

IFN- $\gamma-$ The role of IFN- $\gamma$ in SLE is not fully elucidated. IFN- $\gamma$ is elevated in (New Zealand Black [NZB] $\times$ New Zealand White $[\mathrm{NZW}]) \mathrm{F}_{1}(\mathrm{NZB} / \mathrm{W})$ lupus mice, where it correlates with disease. In addition, administration of IFN- $\gamma$ accelerates murine lupus, while anti-IFN- $\gamma$ antibody (or soluble IFN- $\gamma$ receptor or IFN- $\gamma$ receptor-immunoglobin) delays the disease [21-23]. Finally, late treatment with IFN- $\gamma$ in MRL/lpr mice accelerates SLE, while early treatment protects from disease [24].

In humans, elevated serum IFN- $\gamma$ correlates with disease activity and kidney involvement in SLE patients [25]. However, some studies show an increase of IFN- $\gamma$ in SLE patients and other studies find decreased titers of IFN- $\gamma$ in lupus nephritis [26].

AMG 811-The safety, tolerability, pharmacokinetics and pharmacodynamics of multiple doses of this human mAb to IFN- $\gamma$ are under investigation in a Phase Ib, randomized, multicenter study in SLE patients with and without glomerulonephritis. 
- IL-1

IL-1 includes the proinflammatory cytokines IL- $1 \alpha$ and IL-1 $\beta$. IL-1 binds to IL-1 receptor (IL-1R). The IL-1R antagonist (IL-1Ra) competes for receptor binding with IL-1 $\alpha$ and IL-1 $\beta$, thus blocking these cytokines.

IL-1 is overexpressed in inflamed kidneys of MRL/lpr and NZB/W lupus mice, and low-dose administration of IL-1 accelerates renal disease in the latter strain of mice [3]. IL-1R deficiency causes arthritis in mice, and MRL/lpr mice with nephritis do not respond to therapy with IL-1Ra $[3,27,28]$.

In human SLE, IL- $1 \alpha$ and $-1 \beta$ are increased in glomerulonephritis, and IL- $1 \beta$ is increased in the serum and cerebrospinal fluid of patients with CNS lupus [29,30]. Although kidney involvement associates with low serum levels of IL-1Ra, some reports have shown an increase of IL-1Ra during active disease and a decrease during disease flares [30,31].

Anakinra-This nonglycolated version of the human IL-1Ra (which neutralizes the biological activity of IL-1) has shown both safety and efficacy in improving arthritis in an open trial on four SLE patients, with only short-lasting therapeutic effects in two patients [32].

\section{- IL-6}

IL-6 induces B-cell differentiation to plasma cells, hyperactivity and secretion of antibodies, and also promotes T-cell proliferation, cytotoxic T-cell differentiation and local inflammation. IL- 6 can be induced by TNF- $\alpha$ and IL-1, and signals through the ligand-binding membranebound IL-6R and the nonligand-binding signal transducer gp130. A soluble form of IL-6R, which lacks transmembrane and cytoplasmic domains (and can form a complex with soluble IL-6) is elevated in SLE patients and in experimental lupus nephritis.

Blockade of IL-6R improves renal disease [33]. Similarly, treatment with IL-6 promotes disease, while anti-IL-6 therapy delays lupus nephritis in NZB/W mice [34].

In the serum of active SLE patients, IL-6 is elevated and correlates with disease activity [35]. IL-6 is found in lupus kidneys and in the urine of patients with lupus nephritis [29,36]. Finally, IL-6 is elevated during cardiopulmonary complications of SLE and in the cerebrospinal fluid of SLE patients with neuropsychiatric symptoms [37,38].

Tocilizumab-By binding both the membrane-bound IL-6R and the soluble form of IL-6R, this humanized mAb inhibits IL-6 signaling. An open-label Phase I dosage-escalation study with tocilizumab in SLE patients with mild-to-moderate disease demonstrated improved disease activity scores and amelioration of arthritis, in addition to a decrease in the frequency of circulating plasma cells and reduced IgG and anti-dsDNA a ntibody titers, but also induced neutropenia [39].

- IL-10

IL-10 is generally considered an inhibitory cytokine for T cells and contrasts the activity of other proinflammatory cytokines such as IFN- $\gamma$, TNF- $\alpha$ and GM-CSF. In B cells, IL-10 promotes differentiation and antibody production.

New Zealand Black/White lupus mice treated with anti-IL-10 mAb have reduced anti-DNA antibody titers and a delay in the onset of proteinuria and glomerulonephritis. Conversely, their treatment with IL-10 associates with accelerated disease [40]. However, these effects appear to be strain dependent [41]. 
IL-10 levels are elevated in sera of SLE patients and correlate with clinical and sero-logical disease activities [42]. Treatment of cells from lupus patients with anti-human IL-10 antibody reduces antibody production [43]. Interestingly, the dysregulation of IL-10 in SLE patients is linked to certain genetic polymorphisms [44].

B-N10 - In the absence of a human (or humanized) mAb to IL-10, the murine anti-IL-10 mAb B-N10 was used to neutralize IL-10 in a small uncontrolled, open-label study in patients with relatively mild disease [45]. Disease activity improved and inactivity was observed in SLE patients up to 6 months after treatment [45]. However, all patients developed antibodies against the murine $\mathrm{mAb}$ [45].

\section{B-lymphocytic stimulator}

B-lymphocyte stimulator (BLyS), a member of the TNF family, is also known as B-cellactivating factor (BAFF), TALL-1; THANK; and zTNF4. BLyS can be released in a soluble form or can be expressed as a transmembrane protein on monocytes, DCs, activated T cells and some malignant B cells. The production of BLyS is favored by IFN- $\gamma$, IFN- $\alpha$, IL-10, GCSF and CD40L [46,47]. Elevated levels of BLyS associate with lupus-like disease in mice, and SLE patients have elevated serum levels of BLyS [48-50].

B-lymphocyte stimulator interacts with transmembrane receptors that are not present in early B-cell precursors or in pre-B cells and are mainly present in mature B cells [51-53]. They are the TNF receptor superfamily member 13C (TNFRSF13C), also known as BAFF receptor (BAFF-R) or CD268; the TNFRSF13B, also known as transmembrane activator and calcium modulator and cyclophylin ligand interactor (TACI) or CD267; and the TNFRSF17, also known as B-cell maturation antigen (BCMA) or CD269. The stimulation of all three receptors promotes B-cell differentiation and proliferation by increasing the intracellular levels of NF$\kappa \mathrm{B}$, but the three receptors have differing binding affinities for BLyS. TACI has the worst affinity for BLyS and actually has higher affinity for a molecule similar to BLyS, termed a proliferation inducing ligand (APRIL). BCMA has an intermediate binding phenotype and can bind either BAFF or APRIL.

B-lymphocyte stimulator appears to play an important role in the differentiation of B cells into plasma cells. Signaling through BAFF-R and BCMA increases the levels of the antiapoptotic protein Bcl-2, thus promoting B-cell survival, while blockade of the BLyS-BAFF-R pathway (with anti-BLyS mAb or fusion proteins) leads to a reduced number of peripheral B cells [48].

\section{- Benlysta (belimumab)}

Belimumab is a fully human $\operatorname{IgG} 1 \lambda \mathrm{mAb}$ that binds BLyS, thus inhibiting its activities on B cells. When Phase II studies failed to show an efficacy of belimumab in reducing SLE, it was found that an improvement in measures of SLE disease activity had occurred in serologically active patients. In addition, the drug required some time to work because better therapeutic effects were observed at 52 weeks [54]. Thus, after missing the end point in the Phase II lupus trial, belimumab entered two double-blind, placebo-controlled, multicenter Phase III trials evaluating the drug's efficacy, safety, tolerability and impact on quality of life in seropositive SLE patients at 52 weeks and at 76 weeks. These two Phase III trials, termed BLISS-52 and BLISS-76, recruited patients in different continents and used a newly designed individual responder index (IRI), similar to that used in RA, to measure an individual patient's improvement from baseline. The IRI took into account a reduction from baseline of SELENA SLEDAI and BILAG scores, and the physician global assessment (these parameters were analyzed on an ad hoc-adjusted intention-to-treat). At 52 weeks, both the BLISS-52 and the 
BLISS-76 trials met their primary end points, and a statistically significant improvement versus the placebo group was observed in both studies [101].

B-lymphocyte stimulator has also been targeted by other biologics such as AMG 623 and BR3Fc [55]. Preclinical studies have also tested anti-BR3 antibodies that block BLyS-dependent $\mathrm{B}$-cell survival in vitro and in vivo [56]. Interestingly, anti-BR3 antibodies reduce the numbers of B cells more effectively than anti-BLyS mAb, BR3-Fc and TACI-Fc [57].

\section{- A-623 \& BR3-Fc}

A-623, formerly AMG 623, is a polypeptide fusion protein (peptibody) that inhibits B-cell survival and maturation by neutralizing BLyS. A-623 is currently in Phase II clinical trials. $\mathrm{BR} 3-\mathrm{Fc}$ (briobacept) is a homodimeric fusion glycoprotein of the extracellular ligand-binding portion of BAFF-R and the Fc portion of an $\mathrm{IgG}_{1}$ that blocks BLyS from binding to BAFF-R, thus inhibiting activation and promoting a poptosis of B cells.

Both AMG 623 and BR3-Fc are in clinical trials and appear well tolerated. Their efficacy in SLE is unknown at present [58-59].

\section{- Atacicept}

Atacicept is a recombinant fusion protein made of the extracellular ligand-binding portion of TACI (see previous section) fused to the Fc portion of a human IgG. It is a soluble receptor that binds BLyS and APRIL, thus blocking the activation of TACI. Although a Phase II/III lupus nephritis trial that evaluated dose-effectiveness in SLE patients gave disappointing results and the study was discontinued owing to the development of severe infections in some patients, a new Phase II/III trial of atacicept in generalized SLE is ongoing [60].

\section{Conclusion}

Biologics have dramatically improved the clinical management of several autoimmune diseases. In SLE, where multiple immune imbalances associate with a significant complexity and a diversity of clinical disease manifestations, the use of mAbs to cytokines has shown rapid advancement and potential promise. Concerns with the use of biologics remain the risk of immediate and delayed toxicities and the development of drug resistance. Although no biological response modifiers are currently approved for SLE, it is likely that belimumab will be approved this year, and new open-label trials will soon be added to the list reviewed here. While most data available derive from open-label trials, controlled trials are also underway to confirm the preliminary data in multicenter, randomized trials (Table 1). Importantly, mechanistic studies are paralleling some of those studies, so that an increased understanding of some cellular and molecular events associated with clinical and serologic responses can facilitate and possibly improve the use and targeted efficacy of selected biologics in SLE.

\section{Future perspective}

Driven by promising data with belimumab and tocilizumab in the recent clinical trials, the field of anticytokine immunotherapy in SLE is likely to expand to include the targeting of additional proinflammatory cytokines in the near future. Even if some trials in SLE have been disappointing (such as the ones involving TNF inhibitors), pitfalls may be somehow instrumental in the design of better trials and to optimize parameters that can ultimately increase effectiveness and reduce side effects in the testing of new drugs in SLE. After approximately half a century without approval of new drugs for SLE, the next decade is most likely to see the addition of biologics such as anticytokine antibodies to the physician's armamentarium in the treatment of SLE. 


\section{Executive summary}

- Systemic lupus erythematosus (SLE) is an incurable disease in which new drugs are required to improve a patient's well-being, clinical disease management and prognosis.

Since proinflammatory cytokines are key elements in the chronic inflammation and tissue damage in SLE, a reduction of their deleterious activity represents a possible therapeutic target.

- Although murine, chimeric, humanized and fully human antibodies have all been considered in SLE, most recent trials aim at employing antibodies carrying the least immunogenicity (eliminating mouse components) to achieve longer-term efficacy.

- Since clinical trials suggested that the blockade of B-lymphocyte stimulator can have beneficial effects on disease in some SLE patients, belimumab (anti-B-lymphocyte stimulator) will probably be approved for SLE therapy in a near future.

- Although very effective in other rheumatic disease, treatment with TNF inhibitors has given disappointing results in clinical trials in SLE.

- While preliminary, recent studies on the use of interferon and IL-6 blockade hold promise as new therapeutics in SLE.

\section{Bibliography}

Papers of special note have been highlighted as:

- of interest

1. Mok CC. Update on emerging drug therapies for systemic lupus erythematosus. Expert Opin. Emerg. Drugs 2010;15(1):53-70. [PubMed: 20148712]

2. Jacob C, McDevitt $H$. Tumour necrosis factor- $\alpha$ in murine autoimmune 'lupus' nephritis. Nature 1988;331(6154):356-358. [PubMed: 2893286]

3. Brennan D, Yui M, Wuthrich R, Kelley V. Tumor necrosis factor and IL-1 in New Zealand Black/ White mice. Enhanced gene expression and acceleration of renal injury. J. Immunol 1989;143(11): 3470-3475. [PubMed: 2584702]

4. Edwards C, Zhou T, Zhang J, et al. Inhibition of superantigen-induced proinflammatory cytokine production and inflammatory arthritis in MRL-lpr/lpr mice by a transcriptional inhibitor of TNF- $\alpha$. J. Immunol 1996;157(4):1758-1772. [PubMed: 8759766]

5. Yokoyama H, Kreft B, Kelley V. Biphasic increase in circulating and renal TNF- $\alpha$ in MRL-lpr mice with differing regulatory mechanisms. Kidney Int 1995;47(1):122-130. [PubMed: 7731137]

6. Aringer M, Smolen J. SLE - complex cytokine effects in a complex autoimmune disease: tumor necrosis factor in systemic lupus erythematosus. Arthritis Res. Ther 2003;5(4):172-177. [PubMed: 12823847]

7. Gabay C, Cakir N, Moral F, et al. Circulating levels of tumor necrosis factor soluble receptors in systemic lupus erythematosus are significantly higher than in other rheumatic diseases and correlate with disease activity. J. Rheumatol 1997;24(2):303-308. [PubMed: 9034987]

8. Lacki J, Leszczynski P, Kelemen J, Müller W, Mackiewicz S. Cytokine concentration in serum of lupus erythematosus patients: the effect on acute phase response. J. Med 1997;28(1-2):99-107. [PubMed: 9249616]

9. Studnicka-Benke A, Steiner G, Petera P, Smolen J. Tumour necrosis factor $\alpha$ and its soluble receptors parallel clinical disease and autoimmune activity in systemic lupus erythematosus. Br. J. Rheumatol 1996;35(11):1067-1074. [PubMed: 8948291]

10. Charles P, Smeenk R, De Jong J, Feldmann M, Maini R. Assessment of antibodies to double-stranded DNA induced in rheumatoid arthritis patients following treatment with infliximab, a monoclonal 
antibody to tumor necrosis factor $\alpha$ : findings in open-label and randomized placebo-controlled trials. Arthritis Rheum 2000;43(11):2383-2890. [PubMed: 11083258]

11. De Rycke L, Kruithof E, Van Damme N, et al. Antinuclear antibodies following infliximab treatment in patients with rheumatoid arthritis or spondylarthropathy. Arthritis Rheum 2003;48(4):1015-1023. [PubMed: 12687543]

12. Shakoor N, Michalska M, Harris C, Block J. Drug-induced systemic lupus erythematosus associated with etanercept therapy. Lancet 2002;359(9306):579-580. [PubMed: 11867114]

13. Carlson E, Rothfield N. Etanercept-induced lupus-like syndrome in a patient with rheumatoid arthritis. Arthritis Rheum 2003;48(4):1165-1166. [PubMed: 12687569]

14. Stokes M, Foster K, Markowitz G, et al. Development of glomerulonephritis during anti-TNF- $\alpha$ therapy for rheumatoid arthritis. Nephrol. Dial. Transplant 2005;20(7):1400-1406. [PubMed: 15840673]

15. Aringer M, Steiner G, Graninger W, et al. Effects of short-term infliximab therapy on autoantibodies in systemic lupus erythematosus. Arthritis Rheum 2007;56(1):274-279. [PubMed: 17195231]

16. Hayat S, Uppal S. Therapeutic efficacy and safety profile of infliximab in active systemic lupus erythematosus. Mod. Rheumatol 2007;17(2):174-177. [PubMed: 17437178]

17. Aringer M, Graninger WB, Steiner G, Smolen J. Safety and efficacy of tumor necrosis factor $\alpha$ blockade in systemic lupus erythematosus: an open label study. Arthritis Rheum 2004;50(10):31613169. [PubMed: 15476222]

18. Feng X, Wu H, Grossman J, et al. Association of increased interferon-inducible gene expression with disease activity and lupus nephritis in patients with systemic lupus erythematosus. Arthritis Rheum 2006;54(9):2951-2962. [PubMed: 16947629]

19 m. Baechler E, Batliwalla F, Karypis G, et al. Interferon-inducible gene expression signature in peripheral blood cells of patients with severe lupus. Proc. Natl Acad. Sci. USA 2003;100(5):26102615. [PubMed: 12604793] [Approximately half of systemic lupus erythematosus (SLE) patients have dysregulated expression of genes in the IFN pathway, and this IFN gene expression 'signature' can serve as a marker for greater disease severity.]

20. Bengtsson A, Sturfelt G, Truedsson L, et al. Activation of type I interferon system in systemic lupus erythematosus correlates with disease activity but not with antiretroviral antibodies. Lupus 2000;9 (9):664-671. [PubMed: 11199920]

21. Balomenos D, Rumold R, Theofilopoulos A. Interferon- $\gamma$ is required for lupus-like disease and lymphoaccumulation in MRL-lpr mice. J. Clin. Invest 1998;101(2):364-371. [PubMed: 9435308]

22. Jacob $\mathrm{C}$, van der Meide $\mathrm{P}, \mathrm{McDevitt} \mathrm{H}$. In vivo treatment of $(\mathrm{NZB} \times \mathrm{NZW}) \mathrm{F}_{1}$ lupus-like nephritis with monoclonal antibody to $\gamma$ interferon. J. Exp. Med 1987;166(3):798-803. [PubMed: 3114409]

23. Lawson B, Prud'homme G, Chang Y, et al. Treatment of murine lupus with cDNA encoding IFN$\gamma R / F c$. J. Clin. Invest 2000;106(2):207-215. [PubMed: 10903336]

24. Nicoletti F, Di Marco R, Zaccone P, et al. Dichotomic effects of IFN- $\gamma$ on the development of systemic lupus erythematosus-like syndrome in MRL-lpr/lpr mice. Eur. J. Immunol 2000;30(2):438-447. [PubMed: 10671199]

25. Uhm W, Na K, Song G, et al. Cytokine balance in kidney tissue from lupus nephritis patients. Rheumatology (Oxford) 2003;42(8):935-938. [PubMed: 12730502]

26. Min D, Cho M, Cho C, et al. Decreased production of interleukin-12 and interferon- $\gamma$ is associated with renal involvement in systemic lupus erythematosus. Scand. J. Rheumatol 2001;30(3):159-163. [PubMed: 11469526]

27. Horai R, Saijo S, Tanioka H, et al. Development of chronic inflammatory arthropathy resembling rheumatoid arthritis in interleukin 1 receptor antagonist-deficient mice. J. Exp. Med 2000;191(2): 313-320. [PubMed: 10637275]

28. Kiberd B, Stadnyk A. Established murine lupus nephritis does not respond to exogenous interleukin-1 receptor antagonist; a role for the endogenous molecule? Immunopharmacology 1995;30(2):131137. [PubMed: 8530254]

29. Takemura T, Yoshioka K, Murakami K, et al. Cellular localization of inflammatory cytokines in human glomerulonephritis. Virchows Arch 1994;424((5):459-464. [PubMed: 8032526] 
30. Sturfelt G, Roux-Lombard P, Wollheim F, Dayer J. Low levels of interleukin-1 receptor antagonist coincide with kidney involvement in systemic lupus erythematosus. Br. J. Rheumatol 1997;36(12): 1283-1289. [PubMed: 9448589]

31. Suzuki H, Takemura H, Kashiwagi H. Interleukin-1 receptor antagonist in patients with active systemic lupus erythematosus. Enhanced production by monocytes and correlation with disease activity. Arthritis Rheum 1995;38(8):1055-1059. [PubMed: 7639800]

32. Ostendorf B, Iking-Konert C, Kurz K, et al. Preliminary results of safety and efficacy of the interleukin 1 receptor antagonist anakinra in patients with severe lupus arthritis. Ann. Rheum. Dis 2005;64(4): 630-633. [PubMed: 15345502]

33. Kiberd B. Interleukin-6 receptor blockage ameliorates murine lupus nephritis. J. Am. Soc. Nephrol 1993;4(1):58-61. [PubMed: 8400070]

34 .. Finck BK, Chan B, Wofsy D. Interleukin 6 promotes murine lupus in NZB/NZW F 1 mice. J. Clin. Invest 1994;94(2):585-591. [PubMed: 8040314] [By demonstrating that antibodies to IL-6 can suppress murine lupus, this study provides a rationale for therapeutic use of IL-6 blockade in SLE.]

35. Stuart R, Littlewood A, Maddison P, Hall N. Elevated serum interleukin-6 levels associated with active disease in systemic connective tissue disorders. Clin. Exp. Rheumatol 1995;13(1):17-22. [PubMed: 7774098]

36. Horii Y, Iwano M, Hirata E, et al. Role of interleukin-6 in the progression of mesangial proliferative glomerulonephritis. Kidney Int 1993;39:S71-75.

37. Yoshio T, Masuyama J, Kohda N, et al. Association of interleukin 6 release from endothelial cells and pulmonary hypertension in SLE. J. Rheumatol 1997;24(3):489-495. [PubMed: 9058654]

38. Alcocer-Varela J, Aleman-Hoey D, Alarcon-Segovia D. Interleukin-1 and interleukin-6 activities are increased in the cerebrospinal fluid of patients with CNS lupus erythematosus and correlate with local late T-cell activation markers. Lupus 1992;1(2):111-117. [PubMed: 1301962]

39 . Illei GG, Shirota Y, Yarboro CH, et al. Tocilizumab in systemic lupus erythematosus. data on safety, preliminary efficacy, and impact on circulating plasma cells from an open-label Phase I dosageescaltion study. Arthritis Rheum 2010;62(2):542-552. [PubMed: 20112381] [Results of this clinical trial indicate promising clinical and serologic responses to tocilizumab in SLE patients, and that neutropenia may limit the maximum dosage of the drug.]

40. Ishida H, Muchamuel T, Sakaguchi S, et al. Continuous administration of anti-interleukin 10 antibodies delays onset of autoimmunity in NZB/W F 1 mice. J. Exp. Med 1994;179(1):305-310. [PubMed: 8270873]

41. Yin Z, Bahtiyar G, Zhang N, et al. IL-10 regulates murine lupus. J. Immunol 2002;169(4):2148-2155. [PubMed: 12165544]

42. Houssiau F, Lefebvre C, Vanden Berghe M, et al. Serum interleukin 10 titers in systemic lupus erythematosus reflect disease activity. Lupus 1995;4(5):393-395. [PubMed: 8563734]

43. Llorente L, Zou W, Levy Y, et al. Role of interleukin 10 in the B lymphocyte hyperactivity and autoantibody production of human systemic lupus erythematosus. J. Exp. Med 1995;181(3):839_ 844. [PubMed: 7869046]

44. Llorente L, Richaud-Patin Y, Couderc J, et al. Dysregulation of interleukin-10 production in relatives of patients with systemic lupus erythematosus. Arthritis Rheum 1997;40(8):1429-1435. [PubMed: 9259422]

45. Llorente L, Richaud-Patin Y, García-Padilla C, et al. Clinical and biologic effects of antiinterleukin-10 monoclonal antibody administration in systemic lupus erythematosus. Arthritis Rheum 2000;43(8):1790-1800. [PubMed: 10943869]

46. Litinskiy M, Nardelli B, Hilbert D, et al. DCs induce CD40-independent immunoglobulin class switching through BLyS and APRIL. Nat. Immunol 2002;3(9):822-829. [PubMed: 12154359]

47. Scapini P, Nardelli B, Nadali G, et al. G-CSF-stimulated neutrophils are a prominent source of functional BLyS. J. Exp. Med 2003;197(3):297-302. [PubMed: 12566413]

48 . Gross J, Dillon S, Mudri S, et al. TACI-Ig neutralizes molecules critical for B cell development and autoimmune disease. Impaired B cell maturation in mice lacking BLyS. Immunity 2001;15(2): 289-302. [PubMed: 11520463] [Describes the roles of B-lymphocyte stimulator (BLyS) and a proliferation-inducing ligand on B-cell development and suggests that BLyS is required for the development of most but not all mature peripheral B cells.] 
49 m. Stohl W, Metyas S, Tan S, et al. B lymphocyte stimulator overexpression in patients with systemic lupus erythematosus: longitudinal observations. Arthritis Rheum 2003;48(12):3475-3486. [PubMed: 14673998] [Demonstrates that SLE patients have dysregulated BLyS and that BLyS antagonism has beneficial therapeutic potential.]

50. Stohl W. SLE - systemic lupus erythematosus: a BLySful, yet BAFFling, disorder. Arthritis Res. Ther 2003;5(3):136-138. [PubMed: 12723979]

51. Ng L, Sutherland A, Newton R, et al. B cell-activating factor belonging to the TNF family (BAFF)$\mathrm{R}$ is the principal BAFF receptor facilitating BAFF costimulation of circulating $\mathrm{T}$ and $\mathrm{B}$ cells. $\mathrm{J}$. Immunol 2004;173(2):807-817. [PubMed: 15240667]

52 . Cancro MP, D'Cruz DP, Khamashtam MA. The role of B lymphocyte stimulator (BLyS) in systemic lupus erythematosus. J. Clin. Invest 2009;119(5):1066-1073. [PubMed: 19411764] [Overview on the mechanism of action of BLyS on B cells, its role in SLE and its targeting as a therapeutic approach in the treatment of SLE.]

53. Seshasayee D, Valdez P, Yan M, et al. Loss of TACI causes fatal lymphoproliferation and autoimmunity, establishing TACI as an inhibitory BLyS receptor. Immunity 2003;18(2):279-288. [PubMed: 12594954]

54. Belimumab: anti-BLyS human monoclonal antibody, anti-BLyS monoclonal antibody, BmAb, human monoclonal antibody to B-lymphocyte stimulator. Drugs RD 2008;9(3):197-202.

55. von Bülow G, van Deursen J, Bram R. Regulation of the T-independent humoral response by TACI. Immunity 2001;14(5):573-582. [PubMed: 11371359]

56. Lee C, Hymowitz S, Wallweber H, et al. Synthetic anti-BR3 antibodies that mimic BAFF binding and target both human and murine B cells. Blood 2006;108(9):3103-3111. [PubMed: 16840730]

57. Lin W, Gong Q, Seshasayee D, et al. Anti-BR3 antibodies: a new class of B-cell immunotherapy combining cellular depletion and survival blockade. Blood 2007;110(12):3959-3967. [PubMed: 17687108]

58. Stohl W, Merrill JT, Looney RJ, et al. Phase 1a single- and Phase 1b multiple-dose studies of AMG 623 (an anti-BAFF peptibody) in systemic lupus erythematosus (SLE). Arthritis Rheum 2008;58 (9):S565-S566.

59. Fleischmann R, Wei N, Shaw M, et al. BR3-Fc Phase I study: safety, pharmacokinetics (PK) and pharmacodynamic (PD) effects of a novel BR3-Fc fusion protein in patients with rheumatoid arthritis. Arthritis Rheum 2006;54(9):S229-S230.

60. Ratner M. Human Genome Sciences trial data wow lupus community. Nat. Biotechnol 2009;27(9): 779-780. [PubMed: 19741611]

101. BENLYSTA® (belimumab)www.hgsi.com/belimumab.html 


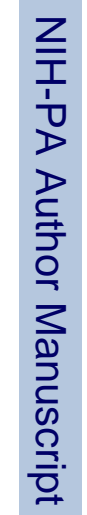

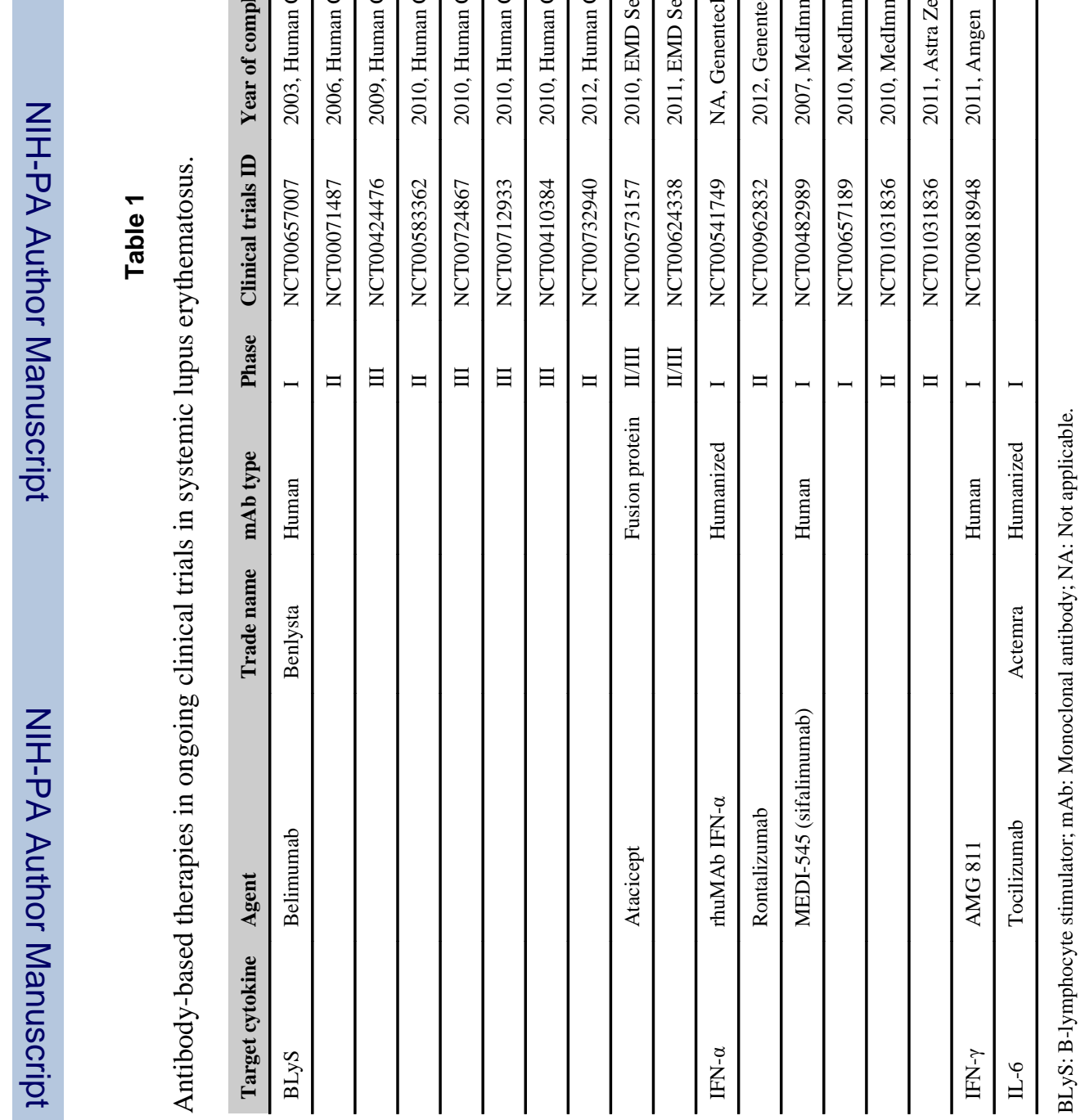

